\title{
Relationship between 5-HTTLPR polymorphism and post-stroke depression
}

\author{
W.Y. Guo ${ }^{1,4 *}$, Z.H. Zhang ${ }^{2 *}$, J.L. $\mathrm{Mu}^{3}$, D. Liü, L. Zhao ${ }^{2}$, Z.Y. Yao ${ }^{4,5}$ and J.G. Song ${ }^{3}$ \\ ${ }^{1}$ College of Life Science and Technology, Xinxiang Medical University, Xinxiang, \\ Henan, China \\ 2Department of Psychosomatic Medicine, \\ The Second Affiliated Hospital of Xinxiang Medical University, Xinxiang, Henan, \\ China \\ ${ }^{3}$ Department of Neurology, \\ The Second Affiliated Hospital of Xinxiang Medical University, Xinxiang, Henan, \\ China \\ ${ }^{4}$ Henan Key Lab of Biological Psychiatry, Xinxiang Medical University, Xinxiang, \\ Henan, China \\ ${ }^{5}$ School of Basic Medicine, Xinxiang Medical University, Xinxiang, Henan, China \\ *These authors contributed equally to this study. \\ Corresponding authors: J.G. Song \\ E-mail: songjg62@126.com \\ Genet. Mol. Res. 15 (1): gmr. 15017460 \\ Received August 17, 2015 \\ Accepted November 13, 2015 \\ Published February 19, 2016 \\ DOI http://dx.doi.org/10.4238/gmr.15017460
}

ABSTRACT. Post-stroke depression (PSD) is a mental illness characterized by subjective feelings of depression, cognitive dysfunction, and decreased interest. The serotoninergic system is involved in the pathogenesis of depressive disorders and is regulated by the serotonin transporter gene. The serotonin transporter-linked polymorphic region (5-HTTLPR) has been examined as a factor associated with depression and other mental disorders. This study was performed to explore the relationship between 5-HTTLPR and PSD in a Han Chinese population. In total, 199 patients with PSD and 202 unrelated non-PSD patients were recruited from psychiatric hospitals. Depression was diagnosed using the Diagnostic 
and Statistical Manual of Mental Disorders-Fourth Edition. Blood samples were collected from all patients for 5-HTTLPR genotyping. Genotype and allele frequencies were compared between the two groups. SS genotype frequency was significantly higher in the PSD group than in the non-PSD group. LL genotype frequency was significantly higher in the non-PSD group than in the PSD group $(P<0.01)$. This study describes a positive association between 5-HTTLPR and PSD in a Han Chinese population and provides genetic evidence to support the genetic susceptibility of PSD.

Key words: 5 -HT transporter gene-linked polymorphic region; Gene polymorphism; Post-stroke depression; Stroke

\section{INTRODUCTION}

Post-stroke depression (PSD) is a common complication in stroke patients. It is characterized by a depressed mood, decreased interest, and sleep disorders, and has an adverse effect on the rehabilitation and outcome of patients with the primary disease (Bilge et al., 2008). One epidemiological survey showed that $30-50 \%$ of stroke patients develops depression (Stefano, 2008). PSD leads to a diminished quality of life, delayed recovery of neurological function, increased mortality, and a greater burden on families and society (Hackett et al., 2010). In recent years, much attention has been paid to the serotonin (5-hydroxytryptamine; 5-HT) transporter gene-linked polymorphic region (5-HTTLPR) genotype in PSD patients and the neurotransmitter serotonin hypothesis, but current studies show that the correlation between 5-HTTLPR and PSD is controversial (Fang and Cheng, 2009; Choi-Kwon et al., 2012; Mak et al., 2013). The present study further explores the association between the 5-HTTLPR and PSD from a biological viewpoint in order to provide a theoretical basis for the etiology of PSD.

\section{MATERIAL AND METHODS}

\section{Subjects}

The studied sample group consisted of 199 patients with PSD (101 men and 98 women) and 202 patients with acute stroke without depression (named non-PSD) (102 men and 100 women). Sample characteristics and demographics are shown in Table 1. All individuals were unrelated, living in the North Henan Province of China, and all had biological grandparents of Chinese-Han ancestry. The protocol was approved by the Ethical Committee of the Second Affiliated Hospital of Xinxiang Medical University. Written informed consent was obtained from all participants after the objectives and procedures of the study were fully explained.

\section{Diagnosis and inclusion criteria}

All patients with acute stroke hospitalized at the Second Affiliated Hospital of Xinxiang Medical University were approached regarding participation. Inclusion criteria were as follows: confirmed ischemic stroke by brain computed tomography; ability to complete the necessary investigations and questionnaires; and capacity to understand the objective of the study and 


Table 1. Sample characteristics and demographic data.
\begin{tabular}{l|c|c|c}
\hline & Non-PSD (N = 202) & PSD (N = 199) & P value ${ }^{\mathrm{a}}$ \\
\hline Age, (mean \pm SD) years & $66.9 \pm 7.8$ & $65.8 \pm 5.3$ & 0.677 \\
\hline Gender & & & 101 \\
\hline Male & 102 & 98 & 0.961 \\
\hline Female & 100 & $8.6 \pm 5.1$ & 0.228 \\
\hline Education, (mean \pm SD) years & $8.2 \pm 4.5$ & $35.6 \pm 7.7$ & 0.634 \\
\hline Disease duration, (mean \pm SD) days & $38.3 \pm 6.2$ & & \\
\hline Stroke type & & 152 & \\
\hline Cerebral infarction & 160 & 47 & \multirow{2}{*}{0.574} \\
\hline Cerebral hemorrhage & 42 & & \\
\hline
\end{tabular}

ap value for PSD vs non-PSD using $\chi^{2}$, Fisher exact or Student $t$-tests. SD = standard deviation; PSD $=$ post-stroke depression; non-PSD = with acute stroke without depression.

provide informed consent. Exclusion criteria were: severe physical illnesses that interfered with recovery from stroke; communication difficulties due to dysphasia or dysarthria precluding giving informed consent and questionnaire completion; neuropsychiatric comorbidities including dementia, Parkinson's disease, brain tumor, epilepsy, psychoses, and alcohol or substance dependence; and severe physical illnesses limiting movement prior to stroke.

PSD was diagnosed by at least two experienced psychiatrists according to the Diagnostic and Statistical Manual of Mental Disorders-Fourth Edition (DSM-IV; 1994), and a score $\geq 21$ points on the Hamilton Depression Rating Scale (HAMD-24).

\section{DNA extraction and genotyping}

Peripheral blood samples from the subjects were drawn into vacutainer tubes containing the anticoagulant ethylenediaminetetraacetic acid and were stored at $-70^{\circ} \mathrm{C}$ until use. Genomic DNA was extracted from leukocytes using the RelaxGene Blood DNA System (Tiangen Biotech, Beijing, China). DNA was suspended in TE-buffer for use in genotyping. The primers for amplification of 5-HTTLPR have been described previously (Goenjian et al., 2012). The upstream primer was 5'-ATGCCAGCACCTAACCCCTAATGT-3' and the downstream primer was 5'-GGACCGCAAGGTGGGCGGGA-3'. PCR was performed in a $25-\mu \mathrm{L}$ reaction volume containing $2.5 \mu \mathrm{L}$ 10X PCR buffer, $0.5 \mu \mathrm{L}$ dNTP mix (10 mM), $1 \mu \mathrm{L}$ each primer $(10 \mu \mathrm{M}), 100 \mathrm{ng}$ genomic DNA, $1 \cup$ Taq DNA polymerase (Tiangen Biotech, Beijing, China), and sterile deionized water. PCR conditions were: pre-denaturation at $95^{\circ} \mathrm{C}$ for $10 \mathrm{~min} ; 35$ cycles of denaturation at $95^{\circ} \mathrm{C}$ for 1 min, annealing at $69^{\circ} \mathrm{C}$ for $1 \mathrm{~min}$, and extension at $72^{\circ} \mathrm{C}$ for $1 \mathrm{~min}$; and final extension at $72^{\circ} \mathrm{C}$ for $20 \mathrm{~min}$. Amplification products were separated using $2 \%$ agarose gel electrophoresis and images were obtained using an ultraviolet gel imaging system (Uvitec, Cambridge, UK) after ethidium bromide staining. The amplification fragment was 419 or $376 \mathrm{bp}$. For the purpose of verification, genomic DNA samples were sent for direct sequencing and all showed results consistent with our enzymatic genotyping.

\section{Statistical analysis}

Demographic characteristics were compared between PSD patients and non-PSD patients using Student $t$-tests, $\chi^{2}$ tests, or Fisher exact tests. Deviations in the genotype counts from HardyWeinberg equilibrium were tested using the $\chi^{2}$ test. Statistical differences in genotypic and allelic distributions between two groups were evaluated by the $\chi^{2}$ test with a significance level of 0.05 . 
Odds ratios $(\mathrm{OR})$ and $95 \%$ confidence interval $(95 \% \mathrm{Cl})$ were calculated to evaluate the effects of different alleles on PSD risk.

\section{RESULTS}

After PCR amplification, genotyping was performed by agarose gel electrophoresis. Length variation in the 5-HTTLPR was defined by two variable nucleotide tandem repeat elements. The short variation (S) allele of the 5-HTTLPR polymorphism led to 14 repeats of base pair sequences. In contrast, a long variation (L) allele led to 16 repeats of base pair sequences (Mak et al., 2013). The LL genotype had a band of $419 \mathrm{bp}$; the LS genotype had bands of 419 and $376 \mathrm{bp}$; and the SS genotype had a band of $376 \mathrm{bp}$. The genotype concordance between the BeadStation 500G PCR (Illumina, Inc., San Diego, CA, USA) and DNA sequencing was 100\%.

There was no deviation from the Hardy-Weinberg equilibrium of 5-HTTLPR genotype in the PSD group $\left(\chi^{2}=2.71, P>0.05\right)$ and non-PSD group $\left(\chi^{2}=2.86, P>0.05\right)$. Significant differences were found in genotype $\left(\chi^{2}=16.75, P=0.002\right)$ and allele $\left(\chi^{2}=15.12, P=0.001\right)$ frequencies between the groups. The frequency of the $L$ allele was significantly lower in PSD patients $(35.7 \%)$ than in non-PSD patients $(49.3 \%$; OR $=0.53,95 \% \mathrm{Cl}=0.39-0.72)$. The results are shown in Table 2.

Table 2. 5-HTTLPR genotype and allele frequency distribution.

\begin{tabular}{l|c|c|c|c|c|c|c|c}
\hline \multirow{2}{*}{ Group } & \multicolumn{3}{|c|}{ Genotype } & \multicolumn{2}{c|}{ Allele frequency } & \multicolumn{2}{c}{ P value } \\
\cline { 2 - 8 } & LL & LS & SS & L & S & HWE & Genotype & Allele \\
\hline PSD $(\mathrm{N}=199)$ & $20(10.1)$ & $102(51.2)$ & $77(38.6)$ & $142(35.7)$ & $256(64.3)$ & 0.09 & \multirow{2}{*}{0.002} & \multirow{2}{*}{0.001} \\
\hline Non-PSD $(\mathrm{N}=202)$ & $43(21.3)$ & $113(55.9)$ & $46(22.8)$ & $199(49.3)$ & $205(50.7)$ & 0.09 & \\
\hline OR $(95 \% C l)$ & $0.28(0.15-0.53)$ & $0.54(0.34-0.85)$ & 1 & $0.53(0.39-0.72)$ & 1 & & & \\
\hline
\end{tabular}

$\mathrm{PSD}=$ post-stroke depression; $\mathrm{OR}=$ odds ratio; $\mathrm{HWE}=$ Hardy-Weinberg equilibrium .

\section{DISCUSSION}

A reduced level of 5-HT neurotransmitters is one of the most accepted hypotheses in the pathogenesis of depression (Marazziti et al., 2013). Studies have shown that the 5-HTTLPR short (S) allele is associated with emotion and cognition (Lee et al., 2003). Whether the pathogenesis and predisposing factors for PSD are the same as those for depression itself has been a research focus in recent years. The pathogenesis of PSD is complicated and related to biopsychosocial factors. It is reported that selective serotonin reuptake inhibitors (SSRIs) are effective in treating PSD (Rasmussen et al., 2003; Niedermaier et al., 2004; Robinson et al., 2008), indicating that PSD and depression result in the disruption of 5-HT neurotransmitters. The 5-HT transporter plays a key role during the metabolism of 5-HT and is the drug target of SSRI antidepressants. Its activity is regulated by 5-HTT transcription regulation (Iversen, 2006; Cole et al., 2011). Therefore, the 5-HTT is considered an important candidate in the genetic research of PSD.

It has been shown that $5-H T T$ transcription is regulated by 5-HTTLPR. 5-HTTLPR is composed of long (L) and short (S) allele insertion/deletion polymorphisms, and this change influences gene transcription. The transcription ability of the $S$ allele is inferior to that of the $L$ allele (Gonda et al., 2009), causing low expression of 5-HT at the site of action. Some studies of PSD and 5-HTTLPR have demonstrated that the SS genotype and S allele are associated with the pathogenesis of PSD (Ramasubbu et al., 2008; Kim et al., 2012). Other studies have 
shown that an increase in the $S$ allele or deletion of the $L$ allele in 5-HTTLPR is correlated with the occurrence of major PSD (Fang and Cheng, 2009). 5-HTTLPR is also associated with alterations in vasoreactivity. There are no significant differences in hippocampus volume and neuronal structure between $S$ and $L$ allele carriers (Cole et al., 2011).

Our findings suggest that genotype distribution and allele frequencies of 5-HTTLPR differ significantly between PSD and non-PSD patients. SS genotype distribution and S allele frequencies in PSD patients are higher than in non-PSD patients (Table 1). LL genotype distribution and L allele frequencies are lower in PSD patients than in non-PSD patients (Table 1). This is consistent with previous studies showing that the $S$ allele of 5-HTTLPR may be an independent risk factor for depression (Lee et al., 2005). The S allele is also positively correlated with post-traumatic stress disorder incidence rate (Kolassa et al., 2010). The $L$ allele may be a protective factor and can reduce the incidence of depression (Grabe et al., 2009). The LL genotype may also increase vascular tension during the stressful event, which may cause ischemia, and is associated with the incidence of vascular events (Brummett et al., 2011). Our results show that SS gene carriers may be prone to development of PSD and the $S$ allele may be a susceptibility factor for PSD. Other studies have suggested that 5-HTTLPR is not associated with PSD or depression (LaskySu et al., 2005; Choi-Kwon et al., 2012). These inconsistencies may be explained by different group criteria, sample size, diagnostic criteria, geographic and ethnic background, and different 5-HTTLPR distribution (Fang et al., 2011).

In summary, our results suggest that PSD may be due to genetic susceptibility. Stroke patients with the SS genotype may be more prone to develop depression. This study was limited by failure to explore the correlation between 5-HTTLPR and SSRIs and their effects after stroke. We only studied the gene polymorphisms of 5-HTT without analysis of linkage equilibrium with other polymorphisms. Therefore, a more in-depth subsequent study is required to validate these results.

\section{Conflicts of interest}

The authors declare no conflict of interest.

\section{ACKNOWLEDGMENTS}

The authors thank the patients, their families, and the physicians who allowed us to take clinical data and blood samples. Research supported by the National Natural Science Foundation of China (\#81471349 and \#81201040), the Natural Science Foundation of Henan (\#112300410165 and \#122300413212), the Scientific Research Fund of Xinxiang Medical University (\#ZD2011-20), and the Science and Technology Innovation Platform Project of Xinxiang (\#CP1305).

\section{REFERENCES}

Bilge C, Koçer E, Koçer A and Türk Börü U (2008). Depression and functional outcome after stroke: the effect of antidepressant therapy on functional recovery. Eur. J. Phys. Rehabil. Med. 44: 13-18.

Brummett BH, Siegler IC, Ashley-Koch A and Williams RB (2011). Effects of 5HTTLPR on cardiovascular response to an emotional stressor. Psychosom. Med. 73: 318-322.http://dx.doi.org/10.1097/PSY.0b013e3182118c16

Choi-Kwon S, Han K, Choi S, Suh M, et al. (2012). Poststroke depression and emotional incontinence: factors related to acute and subacute stages. Neurology 78: 1130-1137.http://dx.doi.org/10.1212/WNL.0b013e31824f8090

Cole J, Weinberger DR, Mattay VS, Cheng X, et al. (2011). No effect of 5HTTLPR or BDNF Val66Met polymorphism on hippocampal morphology in major depression. Genes Brain Behav. 10: 756-764.http://dx.doi.org/10.1111/j.1601- 
183X.2011.00714.X

Fang $\mathrm{J}$ and Cheng Q (2009). Etiological mechanisms of post-stroke depression: a review. Neurol. Res. 31: 904-909.http:// dx.doi.org/10.1179/174313209X385752

Fang J, Yan W, Jiang GX, Li W, et al. (2011). Serotonin transporter gene polymorphism in Chinese patients with poststroke depression: a case-control study. Stroke 42: 1461-1463.http://dx.doi.org/10.1161/STROKEAHA.110.598672

Goenjian AK, Bailey JN, Walling DP, Steinberg AM, et al. (2012). Association of TPH1, TPH2, and 5HTTLPR with PTSD and depressive symptoms. J. Affect. Disord. 140: 244-252.

Gonda X, Fountoulakis KN, Rihmer Z, Lazary J, et al. (2009). Towards a genetically validated new affective temperament scale: a delineation of the temperament phenotype of 5-HTTLPR using the TEMPS-A. J. Affect. Disord. 112: 19-29.http://dx.doi. org/10.1016/j.jad.2008.03.012

Grabe HJ, Spitzer C, Schwahn C, Marcinek A, et al. (2009). Serotonin transporter gene (SLC6A4) promoter polymorphisms and the susceptibility to posttraumatic stress disorder in the general population. Am. J. Psychiatry 166: 926-933.http:// dx.doi.org/10.1176/appi.ajp.2009.08101542

Hackett ML, Carter G, Crimmins D, Clarke T, et al. (2010). imProving Outcomes after STroke (POST): results from the randomized clinical pilot trial. Int. J. Stroke 5: 52-56.http://dx.doi.org/10.1111/j.1747-4949.2009.00388.x

Iversen $\mathrm{L}$ (2006). Neurotransmitter transporters and their impact on the development of psychopharmacology. Br. J. Pharmacol. 147 (Suppl 1): S82-S88.http://dx.doi.org/10.1038/sj.bjp.0706428

Kim JM, Stewart R, Bae KY, Kim SW, et al. (2012). Serotonergic and BDNF genes and risk of depression after stroke. J. Affect. Disord. 136: 833-840.http://dx.doi.org/10.1016/j.jad.2011.09.029

Kolassa IT, Ertl V, Eckart C, Glöckner F, et al. (2010). Association study of trauma load and SLC6A4 promoter polymorphism in posttraumatic stress disorder: evidence from survivors of the Rwandan genocide. J. Clin. Psychiatry 71: 543-547.http:// dx.doi.org/10.4088/JCP.08m04787blu

Lasky-Su JA, Faraone SV, Glatt SJ and Tsuang MT (2005). Meta-analysis of the association between two polymorphisms in the serotonin transporter gene and affective disorders. Am. J. Med. Genet. B. Neuropsychiatr. Genet. 133B: 110-115. http://dx.doi.org/10.1002/ajmg.b.30104

Lee JH, Kim HT and Hyun DS (2003). Possible association between serotonin transporter promoter region polymorphism and impulsivity in Koreans. Psychiatry Res. 118: 19-24.http://dx.doi.org/10.1016/S0165-1781(03)00065-9

Lee HJ, Lee MS, Kang RH, Kim H, et al. (2005). Influence of the serotonin transporter promoter gene polymorphism on susceptibility to posttraumatic stress disorder. Depress. Anxiety 21: 135-139.http://dx.doi.org/10.1002/da.20064

Mak KK, Kong WY, Mak A, Sharma VK, et al. (2013). Polymorphisms of the serotonin transporter gene and post-stroke depression: a meta-analysis. J. Neurol. Neurosurg. Psychiatry 84: 322-328.http://dx.doi.org/10.1136/jnnp-2012-303791

Marazziti D, Baroni S, Picchetti M, Piccinni A, et al. (2013). New developments on the serotonin hypothesis of depression: shunt of tryptophan. Riv. Psichiatr. 48: 23-34.

Niedermaier N, Bohrer E, Schulte K, Schlattmann P, et al. (2004). Prevention and treatment of poststroke depression with mirtazapine in patients with acute stroke. J. Clin. Psychiatry 65: 1619-1623.http://dx.doi.org/10.4088/JCP.v65n1206

Ramasubbu R, Tobias R and Bech-Hansen NT (2008). Extended evaluation of serotonin transporter gene functional polymorphisms in subjects with post-stroke depression. Can. J. Psychiatry 53: 197-201.

Rasmussen A, Lunde M, Poulsen DL, Sørensen K, et al. (2003). A double-blind, placebo-controlled study of sertraline in the prevention of depression in stroke patients. Psychosomatics 44: 216-221.http://dx.doi.org/10.1176/appi.psy.44.3.216

Robinson RG, Jorge RE, Moser DJ, Acion L, et al. (2008). Escitalopram and problem-solving therapy for prevention of poststroke depression: a randomized controlled trial. JAMA 299: 2391-2400.http://dx.doi.org/10.1001/jama.299.20.2391

Paolucci S (2008). Epidemiology and treatment of post-stroke depression. Neuropsychiatr. Dis. Treat. 4: 145-154. 